\title{
Learning through story writing
}

\author{
Reem Rachel Abraham ${ }^{1}$, Sharmila Torke ${ }^{1}$
}

As teachers, majority of us strive to implement active learning strategies in the classroom. It is a challenging task to successfully implement useful and meaningful activities within the limited time frame in classroom. Developing writing skills in medical students is an area which is rarely addressed. It is recommended that students should be instructed in writing skills throughout their medical course (ChurHansen, 2000). Medical students should be trained in scientific writing as they are expected to write case reports, research articles and communicate in scientific meetings in their future career (Micic, 2007). Writing provides students with an opportunity to transform information into meaningful and new knowledge (Holiday-Goodman, 1994). It is reported that stories are instrumental in reconstructing and reflecting on important experiences (Sorrell, 2000) and in helping students to picture a patient's situation through his/her eyes (Emden, 1998). The purpose of this report is to describe story writing as an educational experience in physiology. Melaka Manipal Medical College (MMMC), Manipal Campus, Manipal University, India offers the Bachelor of Medicine and Bachelor of Surgery (MBBS) program which is offered on twin campuses. The first two and a half year of academic training is at Manipal, India and the rest at Melaka, Malaysia. Students are taught anatomy, physiology and biochemistry in the first year. The first year physiology curriculum is divided into four blocks, each of 10 weeks duration:

\footnotetext{
${ }^{1}$ Department of Physiology, Melaka Manipal Medical College, Manipal Campus, Manipal University, India 576104

Corresponding author: Dr. Reem Rachel Abraham Department of Physiology, Melaka Manipal Medical College, Manipal Campus, Manipal University, India 576104 Email: reemabraham@yahoo.com Phone: +91-820-2922649 (O)
}

Block 1: Basic concepts, nerve and muscle physiology

Block II: Cardiovascular, respiratory and gastrointestinal physiology

Block III: Endocrine, reproductive and renal physiology

Block IV: Central nervous system and special senses

Endocrinology was taught to a batch of 143 students for about 5 weeks in March - April 2010. The endocrine glands discussed in this period included anterior pituitary, thyroid and adrenal cortex. Students were informed at the commencement of the block that they would be required to write a story on any one endocrine disorder of their choice (by the end of the block) after the topics were taught in the class. It was decided to reward the best story judged by the authors. For the purpose of story writing, students were divided into twelve groups, each group consisting of 11 to 12 students. Each group was asked to submit minimum one story at the end of the block. Students were encouraged to conduct group meetings outside class hours. Much to our surprise, students submitted the stories before the end of the block itself and two stories were submitted by one group. An example of a story written by one group is given in Table 1 . Students commented that story writing helped them to apply their knowledge, remember clinical conditions and their symptoms better and instigated their creative instinct. It also served as an avenue for teamwork and collaborative learning and helped them to revise the topics. Putting thoughts and creative ideas in writing was indeed learning through fun, as commented by the students. Many of them commented that they had lost touch with the art of writing from the time they finished their high school and they were glad that the skills which they thought were lost were nurtured through this activity. However, a few 
students felt that the activity was time consuming as they had to meet outside class hours. Stories are powerful medium through which patients' experiences can be illustrated and important information can be conveyed
(Sorrell, 2000). Based on the quality of the stories and the feedback we received, this activity was found to be a meaningful and enjoyable learning experience for the students.

Table 1: Story (on Cushing Syndrome) written by one group of students

I was a mother of three children after six years of marriage. My husband was working abroad in a multinational company. When I was pregnant with my $3^{\text {rd }}$ child, I decided to quit my job as I thought it would be better to be at home and bring up my children. After delivering my $3^{\text {rd }}$ child, I put on a lot of weight. I thought it was normal as usually after pregnancy, my weight would increase. However, my weight never decreased. Until then, I never suspected anything unusual because I thought it could be due to the fact that I didn't go to work now.

Whenever I was cooking or ironing clothes and I got hurt, my wounds took longer time to get healed. I assumed it was due to the lack of vitamins and started taking supplements. As a couple of months passed, I couldn't do much housework or take care of my children very long any more, like taking them to school or playing with them, etc. I was feeling lethargic and got tired very quickly. Despite the tiredness, I could not sleep, especially at night.

One day I realized I had a hump at the back of my neck and some purple marks on my arm and abdomen. I decided to go to a clinic because this sudden appearance started to worry me. On reaching the clinic, the doctor examined me and quickly wrote a recommendation letter for me to see an endocrinologist.

The next day I went and saw this specialist. He examined me and asked me for how long have I been having the purplish streaks, followed by other questions like, have you been emotionally disturbed lately and so on. The specialist asked for a few laboratory tests to be done. When the lab results came, the specialist informed me that I have an elevated hormone called cortisol, which is secreted from the adrenal gland. On further examination, the specialist found that I had a tumor on my adrenal gland which caused the increased cortisol levels which in turn led to my lethargy, muscle weakness, purple streaks, obesity, poor wound healing and the hump on my back.

The doctor explained to me that when the blood cortisol levels are high, a great deal of protein breakdown will happen, causing thin skin and poor muscle development. So together with the increased fat in my stomach and arms, my skin got overstretched and the tissues in my skin ruptured causing the purplish streaks.

My obesity and the hump which is called buffalo hump was because cortisol increased the formation of fat in my body. Apart from that, cortisol also increases salt and water reabsorption in the kidney. Therefore this retention of water and salt together with the facial fat resulted in my moon face appearance. The specialist explained to me that other symptom such as osteoporosis is likely to occur because cortisol decreases bone formation and bone resorption.

I went back home feeling speechless and shattered. That night I spoke to my husband and informed him about my condition. He told me that he has decided to come home immediately. He scolded me for not informing him about my problem earlier.

He was with me for two days and was shocked to see my condition. He decided to quit his job abroad and stay with me.

\section{References}

Chur-Hansen A. (2000) Medical students' essaywriting skills: criteria-based self-and tutorevaluation and the role of language background, Med Educ, 34, 3, pp.194-198.

Emden C. (1998) Theoretical perspectives of narrative inquiry, Collegian: Journal of Royal College of Nursing, Australia, 5, 2, pp. 30-35.

Holiday-Goodman M. \& Lively B.T. (1994) Development of a teaching module on written and verbal communication skills, Am J Pharm Educ, 58, pp. 257-261.
Micic S. (2007) Teaching medical writing in an integrated skills approach in Belgrade, Journal of the European Medical Writers Association, $16,1$.

Sorrell J. Stories (2000) In the nursing class room: writing and learning through stories, Journal of Advanced Nursing, 22, 3, pp. 600-609. 